\title{
THE INNTERRELATED FACTORS OF ANEMIA LEVEL ON CHRONIC KIDNEY DISEASE PATIENTS POST DIALYSIS IN DIALYSIS UNIT OF BETHESDA HOSPITAL YOGYAKARTA
}

\author{
Vivi Retno Intening, Haryani, Putu Oka Yuli
}

\begin{abstract}
Background of the Research: A Chronic Kidney Disease (CKD) is a kind of disease (or a renal failure) which shows significant number of rising evidence in recent years. A patient of chronic renal failure needs a renal succession therapy such as dialysis in order to make a longer life. When the disease is getting worst, the patient is generally suffering anemia as the effect of the renal damaged. The interrelated factors of the anemia level are: age, sex, the period of dialysis therapy, nutrition status, illness-stadium, and the enclose disease.
\end{abstract}

Significance of the Research: This research is conducted in order to know the interrelated factors of anemia level in chronic renal failure patients post dialysis.

Research Methods: This is a non-experiment correlation research with a cross sectional approximation. The research is conducted in the Dialysis Unit of Bethesda HospitalYogyakarta, from February to March 2009. The researcher uses purposive sampling with 30 respondents. The measurement instrument is observation sheets and hemoglobin tests. The data analysis is done through distribution frequency; Kolmogorov-Smirnov test for the bivariate analyses and Logistic Regression for the multivariate analyses.

Research findings: The research which was conducted on 30 respondents showed result of 93, 3\% easy-anemia patients' sufferings. The age factor, sex, dialysis period, nutrition status, illness-stadium, and the enclose disease were statistically unrelated to the level of anemia, with $p>0$, 05. The statistic accounting of logistic regression showed that the illness-stadium was the most probable factor related to the level of anemia, with $p=0,09 ; C I=0,734$ -

73, 248; $\operatorname{Exp}(B) 7,333$.

Conclusion: The age factor, sex, dialysis period, nutrition status, illness-stadium, and the enclose disease were statistically unrelated to the level of anemia, but the most probable factor related to the level of anemia was the illness-stadium.

Keywords: Chronic Kidney Disease, Anemia Level, Dialysis 